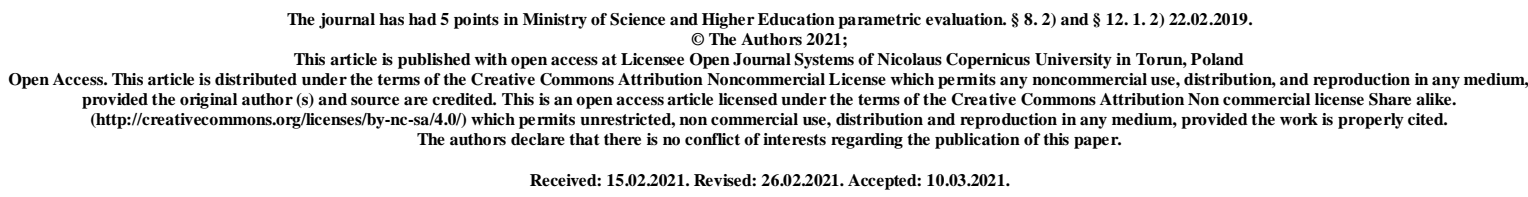

UDK 378.14.015.62

\title{
DIAGNOSTICS OF THE FORMATION OF THE GRAPHIC COMPETENCE OF FUTURE ENGINEERS-EDUCATORS IN THE FIELD OF DIGITAL TECHNOLOGIES
}

\section{Pavlo Ivanovych Koliasa}

\section{Ternopil Volodymyr Hnatiuk National Pedagogical University}

\section{Abstract}

The article analyses the scientific literature on the study of the problem of diagnosing the formation of graphic competence of future engineers-teachers in the field of digital technologies. Based on the analysis, the criteria for the formation of components of graphic competence (value-motivational, activity criteria, personal-creative and communicativeorganizational criteria) are determined. An important aspect of the study is to determine the levels of graphic competence of future engineers-educators in the field of digital technologies, which we defined as: intuitive, reproductive, exploratory and creative, determined by the criteria and indicators of certain components

Keywords: graphic competence; components; criteria; Indicators; levels of formation; engineers-teachers in the field of digital technologies.

Formulation of the problem. The level of graphic competence of pedagogical engineers in the field of digital technologies is an indicator of their success in the professional activity necessary for the quality performance of their duties. The formation of graphic 
competence of future professionals consists of opportunities to solve professional problems, determine ways of working and behaving to perform them. Graphic competence is one of the important prerequisites for the implementation of professional activities by future professionals after graduation. Graphic competence of future engineers-teachers in the field of digital technologies can be shown only during performance by the expert of practical tasks, but preconditions of its formation occur during training.

Therefore, the problem of diagnosing the formation of the components of this competence is important, the solution of which is aimed at improving the effectiveness of learning, including graphic disciplines.

Analysis of recent research. The main task of "diagnosing" is "not only quality management of education, but also individual components of this system," says L. Davydova [3, p. 10-11]. Scientist I. Pidlasy emphasizes that "diagnosing" is a process of visual reflection of the influence of various factors on the educational process of students [7, p. 439]. Thus, diagnosis is an integral part and means of regulating the educational process, which provides quality management training for future professionals.

Diagnosis is based on the developed criteria, so there is a need to study concepts such as "criterion", "indicator" and "level" of the formation of graphic competence of future engineers-teachers in the field of digital technology in the process of their training.

The results of the analysis of scientific works on the formation of graphic competence allow us to conclude that today there are different views on the components of graphic competence and the criteria by which to assess its formation. In the process of interpreting the concepts we rely on the statements of scientists, reference books, pedagogical dictionaries.

The purpose of the article is to determine the main criteria and highlight the levels of formation of the graphic competence of future engineers-educators in the field of digital technologies in the process of their diagnosis.

Presenting main material. In scientific research, the concept of "criterion" is considered as an objective feature on the basis of which the classification or comparison of pedagogical processes that are investigated or studied.

We are impressed by the opinions of such scientists as A. Batarshov [1], O. Karabin [6], V. Kabak [5], O. Potapchuk [8], who believe that the concept of "criterion" is much broader in scope than " indicator ", because the indicator is an integral part of the criteria that identify and qualitatively or quantitatively characterize its essence.

The criterion is expressed by qualitatively formed and defined indicators. We believe that the definition of criteria and indicators of the formation of graphic competence of future 
engineers-teachers in the field of digital technologies should depend on the requirements for the professional activity of the specialist.

The current level of requirements for pedagogical engineers in the field of digital technologies requires the definition of criteria that will reflect not only traditional graphic skills, but also the ability to implement and apply innovative technologies in the process of working on graphic design and tasks. Accordingly, the criteria for the formation of graphic competence will reveal the readiness of future professionals to use the acquired knowledge, which will reflect the dynamics of the development of this competence.

Based on the analysis, we define the concept of "criteria of graphic competence" as a set of indicators, based on which it becomes possible to judge the level of competence, as well as specific and in-depth improvement of its components.

No less important concept in diagnosing the level of formation of graphic competence is "indicator". Scientists who have studied aspects of the outlined problem in their research have identified indicators that should be used as a basis for diagnosing the level of graphic competence of future professionals.

Indicators are determined by visual data on the results and achievements of certain activities, on the basis of which it is possible to draw conclusions about the course of the learning process. Thus, the criterion is the basis for assessing the formation of graphic competence of future engineers of teachers in the field of digital technologies, and the indicator is the data on the basis of which it is possible to draw conclusions about the formation of a component according to certain criteria.

Over the last period of time, scientists pay special attention to the choice of criteria and indicators on the basis of which it is possible to diagnose the level of formation of graphic competence. Researchers develop criteria and indicators that will identify the level of mastery, the quality of students' mastery of educational material, the level of formation of professional qualities and the ability to apply the acquired knowledge in future professional activities.

Therefore, when determining indicators, we take into account such conditions as knowledge of methods and rules for constructing graphic images and the ability to apply digital technologies in the process of solving engineering and graphic problems. This will contribute to a more accurate assessment of the level of formation of the components of graphic competence of future engineers-teachers in the field of digital technologies.

Defining a system of criteria and indicators to assess the formation of components of graphic competence of future engineers-teachers in the field of digital technologies used the 
method of analysis of regulations and educational documentation (Law "On Higher Education" [4], State Standard of Higher Education [9], Psychological pedagogical literature and scientific research (V. Gavrish, I. Dychkivska, V. Slastyonin, L. Tarkhan, etc.) and expert assessment in accordance with the developed criteria and indicators.

Graphic competence of future pedagogical engineers in the field of digital technologies is an integrated concept that encompasses a set of knowledge, skills and abilities of graphic activity, as well as a set of personal qualities. We have identified axiological, cognitive, praxeological and socio-psychological components in the structure of graphic competence. Therefore, as a criterion of the axiological component defined valuemotivational, cognitive component - activity criteria, praxeological - personality-creative criterion, socio-psychological - communicative-organizational criteria.

The value-motivational criterion of the axiological component reflects the level of stable interest of students in graphic activities, which contributes to the emergence of motives for analysis, specification, self-development, self-realization, creative attitude to future professional activity.

Indicators of the value-motivational criterion are: interest in obtaining new graphic knowledge; interest in mastering practical skills of creative projects; a sense of the need for the formation of graphic skills and design abilities; awareness of the need for graphic competence for self-realization in future professional activities; desire to expand scientific horizons, self-development.

These indicators allow us to determine the attitude of the future specialist to the use of modern digital technologies in professional activities, as different motivations determine the different levels of readiness of the specialist for self-development and differences in their behavior.

The activity criterion of the cognitive component is manifested in the readiness for professional activity and provides the ability to work with modern digital technologies (computer-aided design systems) for the successful transfer of graphic knowledge into future professional activity.

The indicators of the activity criterion include: the formation of logical, technical and creative thinking based on the characteristics of personal psychological, perceptual and prognostic components; didactic (effective distribution of the content of the curriculum of graphic disciplines, improvement of forms and means of conducting classes, organization of independent work of students, evaluation of results of their educational activity, methodical abilities and conciseness during teaching material, ability to stimulate students' educational 
interest); technological (possession of tools of modern computer-aided design systems, performance of tasks on two-dimensional and three-dimensional computer modeling, implementation of computer animation and graphic presentation, ability to perform educational projects using modern digital technologies).

The personal-creative criterion of the praxeological component presupposes the ability to use the acquired knowledge and skills in new and non-standard situations, to carry out reflective analysis and correction of information activities.

Indicators of the personal-creative criterion are: implementation of cognitive search during the performance of problematic, educational-cognitive and creative tasks with the use of information-analytical skills; ability to apply the acquired design and engineering, instrumental-technological and artistic-aesthetic skills and experience to solve creative pedagogical and engineering-graphic tasks; independent organization of cognitive activity, self-assessment of work results, application of interdisciplinary connections in solving educational and cognitive tasks.

Socio-psychological component is determined through the expression of communicative and organizational criteria that reflect the level of formation of personal and psychological qualities of the future specialist, providing awareness of the nature and social significance of professional activity, ability to work in a team and objectively self-analyze work, responsibility for physical and mental health.

Indicators of the communicative-organizational criterion are: communicative: ability to apply communicative skills and personal experience while working in a team, develop flexibility of thinking and behavior in the implementation of collective projects, ability to resolve conflicts, ability clearly express their opinions, pedagogical and professional tact; organizational: the ability to organize their own activities (the development of purposefulness, perseverance and responsibility in solving tasks, the ability to manage their own emotional state in professional activities, etc.) and the team.

Given the defined components, criteria and indicators of the formation of graphic competence of future engineers-teachers in the field of digital technologies, we will present them graphically (Pic. 1).

In the context of the researched problem, an important aspect is to determine the levels of graphic competence of future engineers-teachers in the field of digital technologies. 


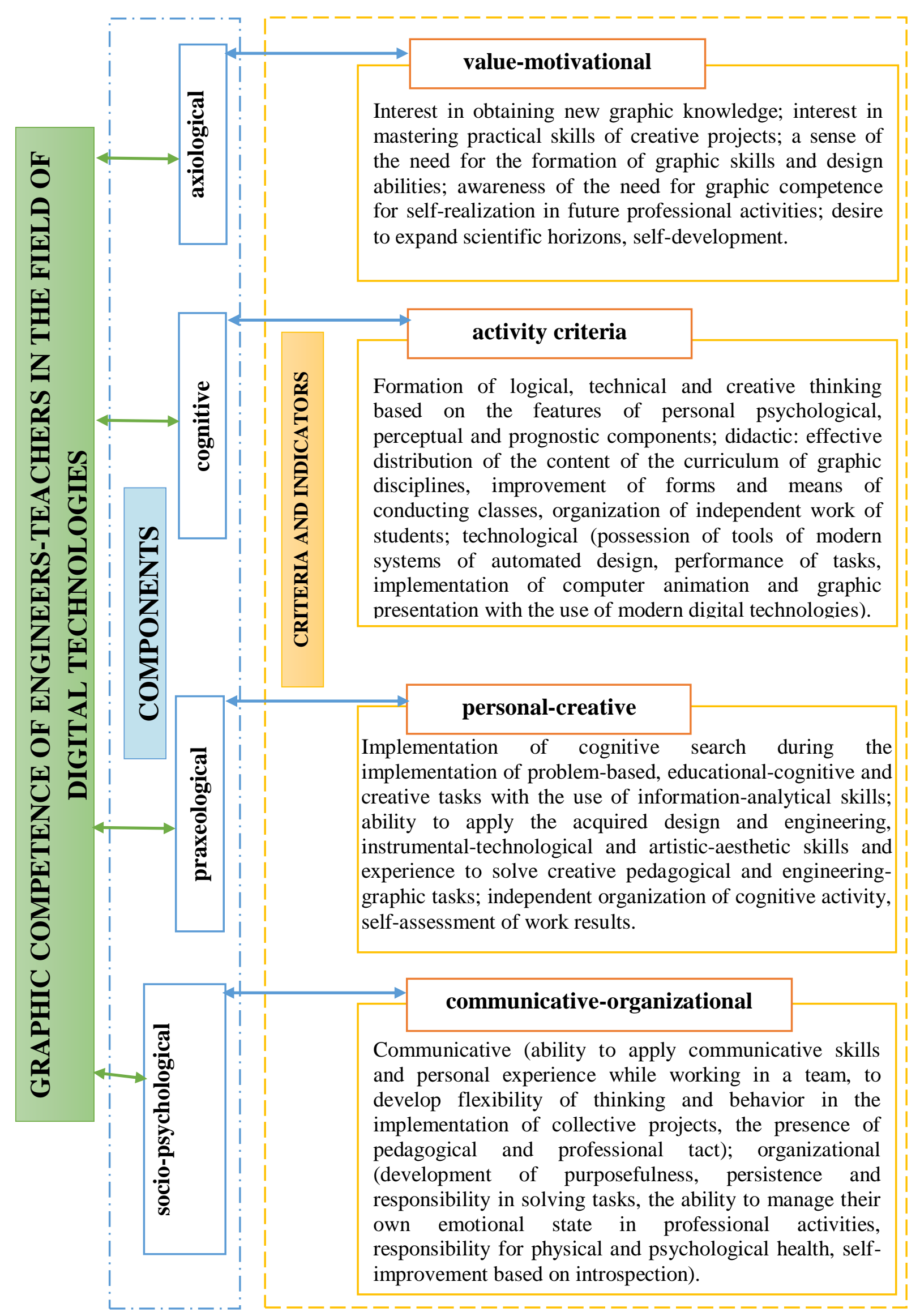

Pic. 1 - The structure of graphic competence of future engineers-teachers in the field of digital technologies 
We are impressed by the opinion of L. Brikova, who identified such levels of formation graphic competence:

- $\quad$ reproductive (student perceives and reproduces basic theoretical knowledge);

- $\quad$ productive (the student has the fundamentals of geometric and graphic base and the ability to apply the acquired theoretical knowledge on the model);

- creative (future engineer is aware of the need to apply graphic knowledge, skills and abilities in new situations) [2, p. 100].

Low and medium level of graphic competence can be diagnosed by performing typical graphic tasks and low complexity tests, a sufficient level involves self-made graphic tasks with more complex elements, and a high level of graphic competence can be determined by creative approaches to solving graphic tasks. Therefore, we believe that the student should use original and creative solutions in the process of graphic activity, which will contribute to the development of competence for solving professional problems.

Based on the analysis, it is established that the formation of graphic competence of future engineers-teachers in the field of digital technologies can be determined by the following levels: intuitive, reproductive, exploratory and creative, which are determined by criteria and indicators of certain components.

Intuitive level is characterized by a lack of interest in acquiring new graphic knowledge and interest in mastering practical skills, has no clear awareness of the need for graphic competence for self-realization in future professional activities. The student reproduces the general terms and concepts of the curriculum of graphic disciplines, knows only the traditional forms and means of conducting classes and evaluating the results of students' learning activities. Intuitive mastery of the tools of computer-aided design systems is manifested. There is no cognitive interest during the implementation of educational and cognitive tasks. Demonstrates low communication skills, is unstable to conflict resolution.

Students of reproductive level show little interest in acquiring new graphic knowledge and interest in mastering practical skills, although they understand the need for graphic competence for self-realization in future professional activities. Independently reproduces the material of the curriculum of graphic disciplines, knows the basic forms and means of conducting classes and evaluating the results of students' educational activities, has methodological abilities. Has the basic tools of modern computer-aided design systems, independently performs typical tasks of two-dimensional and three-dimensional computer modeling, performs computer animation. Communicative skills are manifested while working in a team. Lack of organizational skills. 
At the search level, the student shows considerable interest in obtaining new graphic knowledge, interest in mastering the practical skills of creative projects. Realizes the need for graphic competence for self-realization in future professional activities. Clearly formed logical and technical thinking. Effectively distributes the content of the curriculum of graphic disciplines, has the ability to organize independent work of students, shows methodological abilities and concisely teaches the material.

Fluent in the tools of modern computer-aided design systems, performs individual tasks, is able to participate in the implementation of educational projects. Independently carries out cognitive activity, self-assessment of work results. Uses communication skills and personal experience while working in a team, able to resolve conflicts, clearly and clearly express their thoughts. Poorly expressed organizational skills.

Students of creative level are noted for the formed interest in obtaining new graphic knowledge, mastering practical skills of creative projects, realizes the need for graphic competence for self-realization in future professional activities, shows a desire to expand scientific horizons. Provides effective distribution of the content of the curriculum of graphic disciplines, improves the forms and means for conducting classes, organizes independent work of students, has methodological skills and concisely teaches the material, stimulates students' learning interest. Fluent in the tools of modern computer-aided design systems, performs individual and creative tasks, performs training projects using modern digital technologies. Performs cognitive search while performing problem and creative tasks using information and analytical skills. Uses the acquired design and engineering, instrumentaltechnological and artistic-aesthetic skills to solve creative pedagogical and engineeringgraphic tasks. Independently organizes cognitive activity, carries out self-assessment of results of work in the decision of educational and cognitive problems. Uses communication skills and personal experience while working in a team, has a developed flexibility of thinking and behavior in the implementation of collective projects. Has developed abilities to organize own activity and collective.

Conclusions and prospects for further research. Thus, based on the analysis of literature sources and a thorough analysis of the structure of graphic competence of future engineers-teachers in the field of digital technologies, we have identified the criteria of axiological (value-motivational), cognitive (activity), praxeological (personal-creative) and socio-psychological (communicative) -organizational) components, their indicators and levels of readiness (intuitive, reproductive, exploratory and creative). Their interconnection and successful combination will contribute to the effective formation of graphic competence of 
future engineers-educators in the field of digital technologies, which will meet the requirements of modern digital society.

The problem of effective training of engineers-teachers in the field of digital technologies is their insufficient preparation for professional activity in market conditions and, as a consequence, slow adaptation, lack of modern professional knowledge, responsibility, ingenuity, initiative, creativity, ie unwillingness to work in modern conditions. Obviously, the possibilities of traditional learning have exhausted themselves.

Therefore, to solve the problem of forming the graphic competence of future engineers-teachers in the field of digital technologies it is necessary to determine the most optimal and effective ways to combine components into a holistic system and organizational and pedagogical conditions in which future engineers-teachers will train in digital technologies.

\section{Reference}

1. Batarshev A. V. Diagnostics of professionally important qualities / A. V. Batarshev, I. Yu. Alekseeva, E. V. Mayorova. - SPb. Peter, 2007. - 192 p.

2. Brykova L.V. Formation of graphic culture of the future engineer / L.V. Brykova // Scientific notes: electronic scientific journal of KSU. - 2011. - No. 1 (17). P. 98-106.

3. Davydova LN Pedagogical diagnostics as a component of education quality management: author. dis. for competition scholar. doctor's degree ped. Sciences: spec. 13.00.08 "Theory and methodology of vocational education" / L.N. Davydova. - Astrakhan, $2005 .-40 \mathrm{p}$.

4. Law of Ukraine «On Higher Education» of 25.09.2020 1556-VII: as of 01.02.2021 [Electronic resource]. - Access mode: https://zakon.rada.gov.ua/laws/show/155618\#Text .

5. Kabak V. V. Preparation of future engineers-teachers for professional activity [Text]: dis. cand. ped. sciences: 13.00.04 / Kabak Vitaly Vasilyevich. - Ternopil, 2014. - 206 p.

6. Karabin O. Y. Formation of readiness of future teachers of humanitarian disciplines to work in the information environment [Text]: dis. cand. ped. sciences: 13.00.04 / Karabin Oksana Yosifovna. - Ternopil, 2013. - 200 p.

7. Podlasy I. P. Practical pedagogy or three technologies. Interactive textbook for teachers of the market system of education / Pidlasy I. P. - K.: Publishing House «Word», 2004. $-616 \mathrm{p}$. 
8. Potapchuk O. I. Formation of readiness of future engineers-teachers for professional activity by means of information and communication technologies [Text]: dis. cand. ped. sciences: 13.00.04 / Potapchuk Olga Igorivna. - Ternopil, 2016. - 256 p.

9. Standard of higher education of Ukraine in specialty 015 Vocational education (by specializations) from 11/21/2019 № 1460 https://mon.gov.ua/storage/app/media/vishchaosvita/zatverdzeni\%20standarty/2019/11/22/2019-11-22-015-B.pdf . 